\title{
Foreword
}

\section{A supplement issue on bioengineering and medical techniques}

\author{
Luis Gómez Déniz ${ }^{\mathrm{a}}$ and Carlos Gómez ${ }^{\mathrm{b}, *}$ \\ ${ }^{a}$ Image Technology Center, University of Las Palmas de Gran Canaria, Las Palmas de Gran Canaria, \\ Spain \\ ${ }^{\mathrm{b}}$ Biomedical Engineering Group, University of Valladolid, Valladolid, Spain
}

Welcome to this Supplement Issue (SI) of Technology and Health Care, which gathers a collection of selected papers of maximum interest for researchers in applications of advanced techniques to health care.

As guest editors, only the most relevant papers providing valuable novel insights to challenging biomedical problems found their place in this SI. Such selection has not been easy due to the high level of all manuscripts received. As required, all papers were peer-reviewed by anonymous expert referees following the standard policy of Technology and Health Care.

We hope that all selected papers will provide the readers with current research issues in different fields related with biomedical engineering: medical imaging, biomedical signal processing, genetics, and medical systems, among others.

As guest editors, we strongly appreciate the willingness of the authors to help in organizing this SI. We also extend our gratitude to Ms. Linda Li, who assisted us in all administrative matters in a highly valuable professional manner.

We hope that the readers of Technology and Health Care enjoy this SI.

\footnotetext{
${ }^{*}$ Corresponding author: Carlos Gómez, Biomedical Engineering Group, University of Valladolid, Paseo Belén 15, 47011 Valladolid, Spain. E-mail: carlos.gomez@tel.uva.es.

0928-7329 (c) 2022 - The authors. Published by IOS Press. This is an Open Access article distributed under the terms of the Creative Commons Attribution-NonCommercial License (CC BY-NC 4.0).
} 